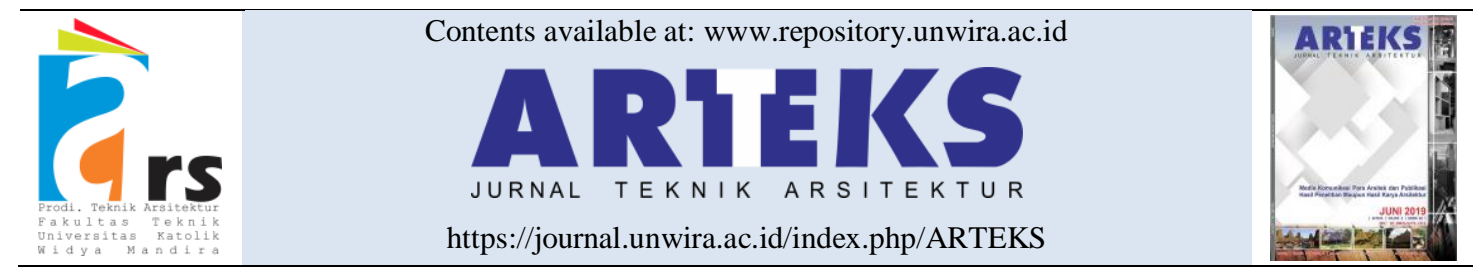

Research paper

doi: $10.30822 /$ arteks.v5i2.372

\title{
Setting fisik graffiti tagging sebagai bentuk vandalisme di Kota Yogyakarta
}

\section{Nino Ardhiansyah}

Program Studi Arsitektur, Fakultas Teknik, Universitas Atma Jaya Yogyakarta

Jl. Grafika no. 2, Yogyakarta-55281, Indonesia

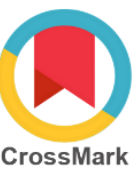

\begin{tabular}{l}
\hline ARTICLE INFO \\
\hline Article history: \\
Received January 22, 2020 \\
Received in revised form February 05, \\
2020 \\
Accepted April 18, 2020 \\
Available online August 01, 2020
\end{tabular}

ABSTRACT

Keywords:

Activity settings

City's identity

Graffiti tagging

Physical settings

Vandalism

Physical settings graffiti tagging as vandalism in Yogyakarta

The spatial identity of a city can be demonstrated through a clean, healthy, and organized city. A city that is clean, organized and free of vandalism is able to meet the city's identity standards. Uncontrolled vandalism perpetrators have increasingly tarnish the privilege of Yogyakarta as a city of education and culture. The act of graffiti tagging is done by writing the name of the gang/group on the media / building in public spaces using spray paint as a form of existence. Graffiti tagging will cause visual pollution that damages the privileges of the City of Yogyakarta. The phenomenon of the rise of graffiti tagging causes problems in the visualization of the representation of Yogyakarta City. The purpose of this study is to identify physical setting factors that influence the activity of graffiti tagging in Yogyakarta City and provide ideas through the preparation of Urban Design Guidelines related to graffiti tagging problems as a form of vandalism that occurs in Yogyakarta City.

Corresponding author: Nino Ardhiansyah Program Studi Arsitektur, Fakultas Teknik, Universitas Atma Jaya Yogyakarta, Indonesia

Email: nino.ardhiansyah@uajy.ac.id This study examines the physical settings and activities on the AM Sangaji corridor which is part of the imaginary axis of the city of Yogyakarta but often becomes the location of vandalism. Data collection is carried out through surveys and literature studies related to building functions, mass, height, color, transparency and setback. The identification results are then analyzed based on each element that is used as a research variable to find building criteria that tend to be objects of vandalism. The results of the study show that locations that are often used as graffiti tagging actions are the places that are located on the main road. The physical setting factors that most influenced the vandalism were lack of vegetation, small building mass, lack of transparency, and narrow setback dimensions.

\section{Pendahuluan}

Identitas ruang yang dimiliki oleh sebuah kota dapat ditunjukkan melalui kota yang bersih, sehat, dan tertata (Liem and Lake 2018; Dianty and Dwisusanto 2020). Kota yang bebas dari vandalism mampu memenuhi standar identitas kota (Wicandra and Angkadjaja 2005). Graffiti tagging merupakan kegiatan vandalisme. Fenomena merebaknya graffiti tagging menyebabkan permasalahan identitas kota (Carollina 2017).

Vandalisme didefinisikan sebagai aktivitas pelanggaran hukum berupa penghancuran atau pengrusakan terhadap properti seseorang (Griffith and Shapland 1979). Orang normal tidak akan 
melakukan perusakan fasilitas umum, karena fasilitas umum dibangun dan disediakan untuk memenuhi kebutuhannya saja. Hanya orang idiot yang akan mencoret-coret rolling door toko atau dinding rumah orang yang sore hari sebelumnya baru selesai dicat oleh pemiliknya (Subandriyo 2002).

Salah satu yang termasuk vandalisme dalam seni dan sering terjadi adalah graffiti. Graffiti yaitu karya seni dengan melukis dipermukaan dinding milik kepentingan umum (Salmah 2015). Efek graffiti tagging telah menimbulkan dampak negatif pada visualisasi kota dan tidak mengindahkan nilai estetis pada konteks tata kota (Fimela 2013).

Dari aspek hukum, Pemerintah Kota Yogyakarta telah mengesahkan peraturan perundangan yang menjadi peraturan teknis turunan dari Undang-undang (UU) Lingkungan Hidup, tata kota, dan kebersihan untuk menanggulangi serta melakukan tindakan preventif adanya tindakan destruktif sebagian masyarakat yang salah satunya diwujudkan atas nama seni dengan menorehkan street arts di dinding atau sarana prasarana fasilitas umum yang berlokasi di ruang publik.

Pelaku aksi vandalisme yang semakin tidak terkontrol mencoreng keistimewaan Yogyakarta sebagai kota pelajar dan kota budaya. Aksi graffiti tagging dilakukan dengan cara menuliskan nama geng/kelompok pada media/bangunan di ruang publik dengan menggunakan cat semprot sebagai wujud eksistensi (Muttaqin 2009). Graffiti tagging akan menimbulkan polusi visual yang merusak keistimewaan Yogyakarta (Kurniasari, Suprihatini, and Lukmantoro 2013).

Pelaku vandalisme di Kota Yogyakarta yang sebagian besar berasal dari kalangan pelajar tentunya sangat mengkhawatirkan bagi dunia pendidikan. Vandalisme memiliki implikasi ekonomi, psikologis, dan aspek yang negatif untuk pendidikan. Vandalisme adalah fenomena yang dipelajari di sekolah dan daerah perumahan yang berdekatan. Peserta didik, khususnya anak laki-laki berusia antara 14-19 tahun menjadi pelaku utama (Wet 2004).

Vandalisme mengancam tidak hanya "aset berwujud" tetapi juga warisan budaya dan sejarah kemanusiaan modern. Sebuah studi terhadap anak-anak, remaja, dan dewasa, serta lingkungan sosial mereka, mengungkapkan mekanisme kesiapan untuk melakukan tindakan perusak yang hadir sejak kecil (Vorobyeva, Kruzhkova, and Krivoshchekova 2015).

Penelitian ini bertujuan untuk menemukan faktor - faktor setting fisik yang mempengaruhi aktifitas grafiti tagging di Kota Yogyakarta serta memberikan gagasan melalui penyusunan Urban Design Guideline terkait permasalahan grafiti tagging sebagai bentuk vandalisme yang terjadi di Kota Yogyakarta.

\section{Metode penelitian}

Metode penelitian yang digunakan adalah deskriptif kualitatif. Perilaku, persepsi, motivasi, dan tindakan dipahami secara menyeluruh. Deskripsi dalam bentuk kata-kata dan bahasa digunakan pada suatu konteks khusus (Lexy 1994).

Pengumpulan data dilakukan melalui survey dan studi pustaka. Data yang dicari antara lain berupa: fungsi bangunan, massa, ketinggian bangunan, warna, transparansi dan setback. Data yang dipetakan dengan menggunakan notasi warna dan data gambar yang diperoleh melalui pengamatan dan penggambaran sketsa-sketsa di lapangan serta identifikasi komponen-komponen yang direkam atau difoto. Metode studi pustaka yaitu cara mengumpulkan data melalui studi literatur terkait setting fisik dan setting aktivitas.

Pengolahan data dilakukan dengan cara mengelompokkan data sesuai variabel yang telah ditentukan. Dari objek studi bangunan di koridor Jalan AM Sangaji dilakukan identifikasi untuk mengetahui elemen-elemen setting fisik bangunan yang berpengaruh terhadap aksi vandalisme. Hasil identifikasi yang ada kemudian didata berdasarkan masing-masing elemen yang dijadikan variabel penelitian untuk menemukan kriteria bangunan yang cenderung menjadi objek vandalisme. 
Tabel 1. Identifikasi pengaruh setting fisik terhadap graffiti tagging secara keseluruhan KEYPLAN

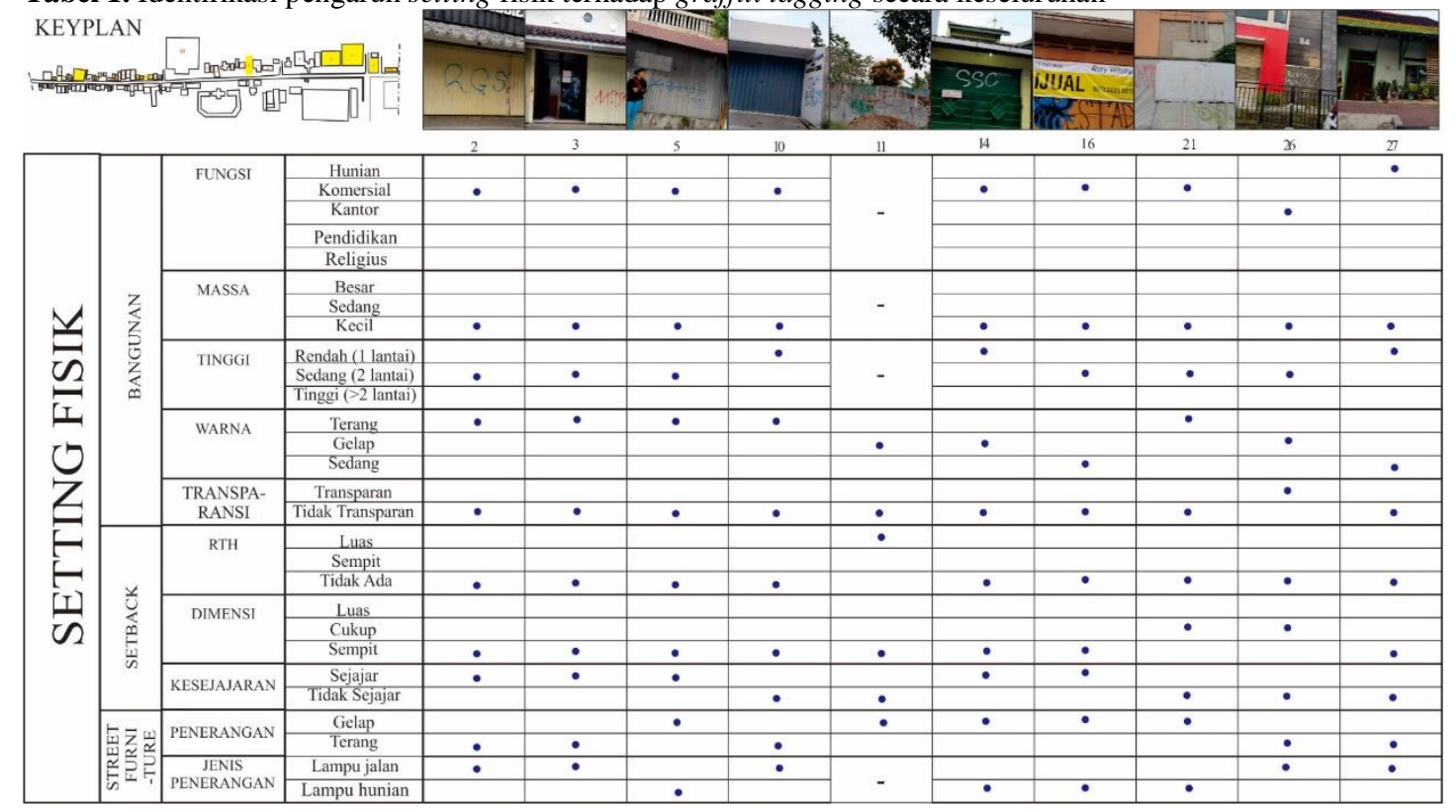

Tabel 2. Identifikasi pengaruh setting fisik terhadap graffiti tagging pada detail bangunan, setback dan street furniture

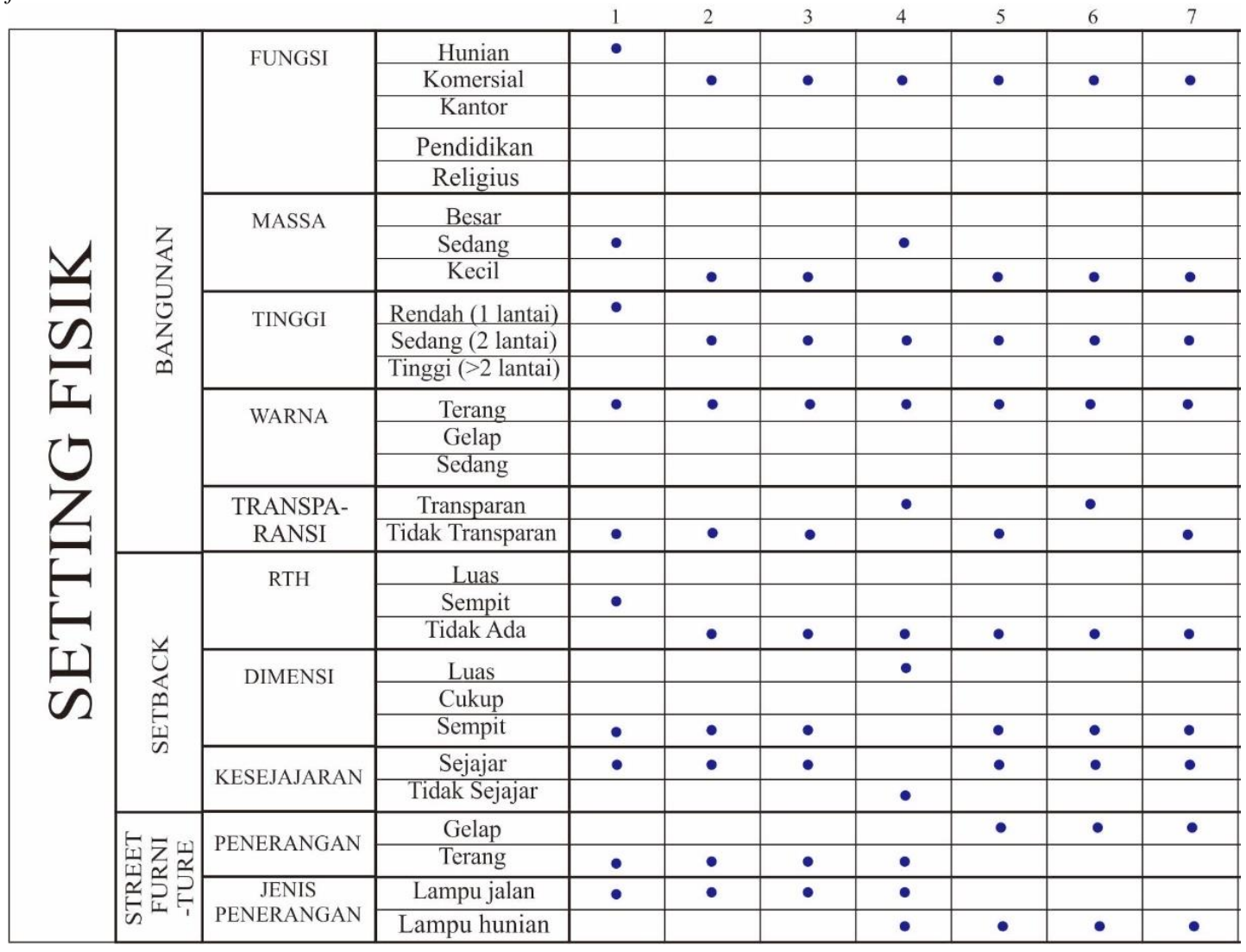




\section{Temuan dan pembahasan}

Kota dilihat dari elemen-elemen fisiknya meliputi: land use, building form and massing, circulation and parking, open space, pedestrian way, activity support, signage, dan preservation (Sirvani 1985).

Studi kota sebagai konfigurasi ruang dikelompokkan dalam teori figure-ground (Ardhiansyah, Widyastuti, and Septiari 2019). Teori ini mengkaji analisis pola, tektur dan solidvoid (Krier 1991).

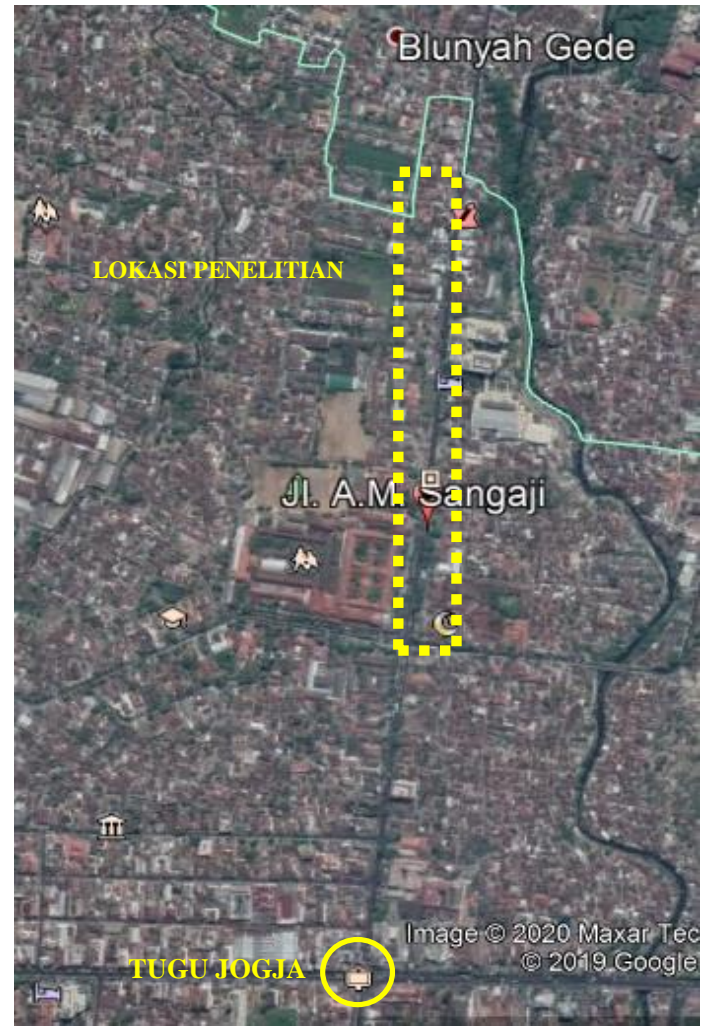

Gambar 1. Rupa bumi koridor Jalan AM Sangaji

Koridor Jalan AM Sangaji dipilih menjadi lokasi penelitian dikarenakan sebagai bagian dari sumbu imajiner Kota Yogyakarta dan merupakan tempat yang rawan akan aksi graffiti tagging. Jalan AM Sangaji merupakan jalan yang membentang dari sebelah Utara Tugu de White Paal hingga ke batas Kota Yogyakarta dengan Kabupaten Sleman. Jalan AM Sangaji termasuk dalam Kecamatan Jetis.

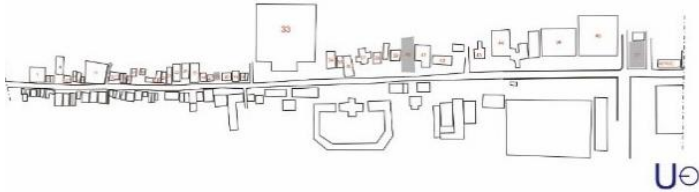

Gambar 2. Figure ground koridor Jalan AM Sangaji

Menurut Rencana Detail Tata Ruang (RDTR) Kota Yogyakarta tahun 2011-2030 pasal 40, Jalan AM Sangaji merupakan jalan kolektor sekunder 1 (KS1) dengan Garis Sempadan Bangunan (GSB) sebesar 12 meter.

Ketentuan Tata Bangunan pada Rencana Detail Tata Ruang dan Peraturan Zonasi Kota Yogyakarta Tahun 2015-2035, Zona Perdagangan dan Jasa (K) Ketentuan Intensitas Bangunan dan tata ruang meliputi: Koefisien Dasar Bangunan (KDB) maksimal 90\%, Tinggi Bangunan maksimal $32 \mathrm{~m}$, Koefisien Lantai Bangunan (KLB) maksimal 6.4, Koefisien Dasar Hijau $(\mathrm{KDH})$ minimal 5\%, lebar jalan (ROW) minimal $3 \mathrm{~m}$, dan GSB minimal 5 meter.

Setting merupakan hubungan antara lingkungan dengan manusia (Subroto 2019; Widodo 2019). Setting fisik meliputi: setback, comfort, features, places, diversity, time, pedestrian, street furniture dan vegetasi. Setting mengkaji hubungan antara elemen fisik lingkungan dengan kegiatan manusia dalam jangka waktu tertentu (Jacobs 1995).

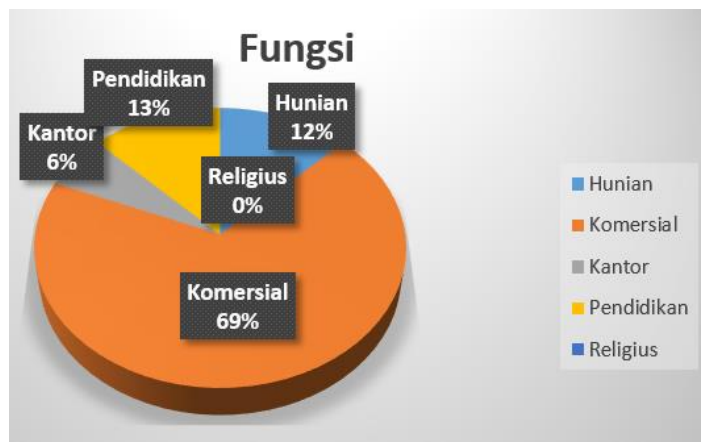

Gambar 3. Identifikasi aksi graffiti tagging pada fungsi bangunan

Data lapangan menunjukkan pada kawasan bagian Timur Jalan AM Sangaji ditemukan bahwa dari 50 bangunan yang dijadikan sebagai objek penelitian terdapat 20 bangunan yang terkena vandalisme. Fungsi bangunan yang paling banyak mengalami aksi vandalisme adalah bangunan dengan fungsi komersial, pendidikan, hunian dan kantor, sedangkan bangunan yang tidak terkena 
aksi vandalisme adalah bangunan dengan fungsi religius.

Tabel 3. Identifikasi aksi graffiti tagging pada fungsi bangunan BARIS TIMUR JALAN AM SANGAJI H Hunian | K Komersial|P Perkantoran | Pd Pendidikan | LKLahan Kosong O Ya $\mid X$ Tidak

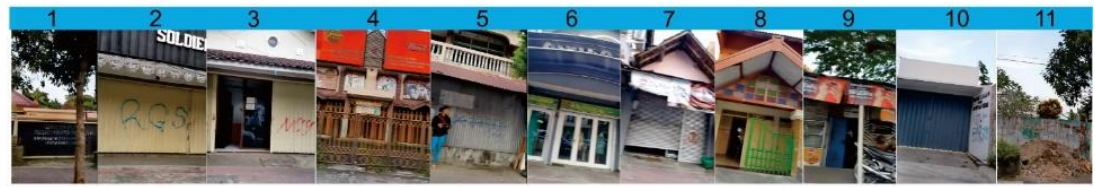

\begin{tabular}{llllllllllll}
\hline FUNGSI & $\mathrm{H}$ & $\mathrm{K}$ & $\mathrm{K}$ & $\mathrm{K}$ & $\mathrm{K}$ & $\mathrm{K}$ & $\mathrm{K}$ & $\mathrm{H}$ & $\mathrm{K}$ & $\mathrm{K}$ & $\mathrm{LK}$ \\
\hline VANDALISME & $\mathrm{X}$ & $\mathrm{O}$ & $\mathrm{O}$ & $\mathrm{X}$ & $\mathrm{O}$ & $\mathrm{X}$ & $\mathrm{X}$ & $\mathrm{X}$ & $\mathrm{X}$ & $\mathrm{O}$ & $\mathrm{O}$ \\
\hline
\end{tabular}

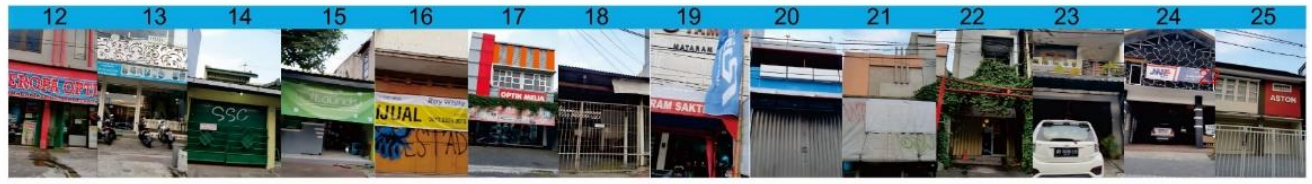

\begin{tabular}{lllllllllllllll}
\hline FUNGSI & $\mathrm{K}$ & $\mathrm{K}$ & $\mathrm{K}$ & $\mathrm{K}$ & $\mathrm{K}$ & $\mathrm{K}$ & $\mathrm{H}$ & $\mathrm{K}$ & $\mathrm{K}$ & $\mathrm{K}$ & $\mathrm{K}$ & $\mathrm{H}$ & $\mathrm{P}$ & $\mathrm{H}$ \\
\hline $\begin{array}{l}\text { VANDALIS- } \\
\text { ME }\end{array}$ & $\mathrm{X}$ & $\mathrm{X}$ & $\mathrm{O}$ & $\mathrm{X}$ & $\mathrm{O}$ & $\mathrm{X}$ & $\mathrm{X}$ & $\mathrm{X}$ & $\mathrm{X}$ & $\mathrm{O}$ & $\mathrm{x}$ & $\mathrm{X}$ & $\mathrm{x}$ & $\mathrm{x}$ \\
\hline
\end{tabular}

Meskipun bangunan komersial menjadi bangunan yang paling dominan terkena aksi vandalisme, bangunan komersial tersebut tidak dapat semata-mata disimpulkan sebagai faktor yang mempengaruhi aksi vandalisme. Hal tersebut dikarenakan, menurut peraturan daerah Rencana Detail Tata Ruang (RDTR) kawasan Jalan AM Sangaji memang merupakan area perdagangan dan jasa sehingga bukan hasil yang mengherankan apabila vandalisme terjadi pada fungsi bangunan komersial yang merupakan fungsi bangunan yang memang mendominasi daerah tersebut.

Berdasarkan data yang telah didapatkan dapat dilihat bahwa perilaku vandalisme cenderung dilakukan pada bangunan bermassa kecil, yaitu dengan persentase sebesar $82 \%$. Sedangkan persentase bangunan bermassa besar yang terkena vandalisme adalah sebesar 18\%. Melalui hasil yang demikian dapat dilihat bahwa massa bangunan memiliki pengaruh yang cukup signifikan terhadap perilaku vandalisme dilihat dari jauhnya persentase antara variasi bentuk massa yang ada pada daerah Jalan AM Sangaji.

Data lapangan menunjukkan bahwa bangunan yang paling banyak mendapatkan perlakuan vandalisme adalah bangunan yang memiliki tingkat ketinggian rendah yaitu bangunan dengan ketinggian satu lantai. Bangunan dengan ketinggian 1 lantai memiliki persentase sebesar $56 \%$. Persentase tersebut berbeda tipis dengan persentase pada bangunan dengan ketinggian sedang yaitu bangunan berlantai 2, yaitu sebesar $44 \%$. Sementara itu, bangunan bertingkat tinggi yang memiliki ketinggian lebih dari 2 lantai sama sekali tidak mengalami aksi vandalisme. Melalui data-data tersebut dapat disimpulkan bahwa perilaku vandalisme cenderung dilakukan pada bangunan tingkat rendah.

Berdasarkan diagram di atas dapat dilihat bahwa bangunan yang cenderung terkena vandalisme adalah bangunan dengan warna gelap yaitu dengan persentase sebesar 40\%. Pada bangunan berwarna sedang dan terang memiliki persentase $30 \%$ terhadap perlakuan vandalisme. Akan tetapi, perbandingan antara warna gelap, sedang, dan terang sangatlah tipis sehingga dapat disimpulkan bahwa elemen warna kecil pengaruhnya terhadap perilaku vandalisme.

Melalui data di atas terlihat bahwa elemen transparansi memiliki pengaruh yang sangat besar terhadap aksi vandalisme. Hal tersebut dibuktikan dengan jauhnya presentaste antara kedua elemen transparansi tersebut. Bangunan dengan transparansi yang rendah menjadi objek favorit pelaku vandalisme, yaitu memperoleh persentase hingga sebesar $80 \%$. Sementara pada bangunan yang memiliki transparansi transparan menjadi 
objek yang kurang diminati oleh para pelaku. Meskipun begitu, beberapa bangunan dengan transparansi transparan tetap menjadi objek vandalisme, yaitu hanya memiliki persentase sebesar $20 \%$.

Faktor vegetasi dan desain lansekap yang ditata dengan baik menyebabkan orang mau mengunjungi dan menjaga ruang publik (Hantono and Pramitasari 2018). Data lapangan menunjukkan bahwa aksi vandalisme lebih sering terjadi pada bangunan yang tidak memiliki penataan vegetasi dan desain lansekap yang baik, yaitu dengan persentase sebesar $85 \%$. Bangunan yang memiliki penataan vegetasi dan desain lansekap yang baik memiliki persentase terkena perilaku vandalisme sebesar $15 \%$.

Hubungan antara vandalisme dan faktor persepsi yang dipicu oleh desain ruang publik di area perumahan. Persepsi visibilitas memberikan efek yang kuat pada vandalisme dan persepsi aksesibilitas memperkuat efek persepsi visibilitas (Mushtaha and Hamid 2016). Data lapangan menunjukkan bahwa pengolahan ruang publik, dalam hal ini ada dan tidaknya ruang terbuka hijau pada bangunan menjadi faktor yang cukup dominan terhadap terjadinya aksi vandalisme.

Berdasarkan hasil pengamatan dan analisis dapat dilihat bahwa aksi vandalisme lebih sering terjadi pada bangunan yang memiliki garis sempadan bangunan yang sangat dekat dengan bibir jalan. Bangunan yang memiliki kesejajaran garis sempadan bangunan memiliki kecenderungan terkena dampak aksi vandalism. Bangunan yang tidak memiliki penerangan yang cukup sangat rentan terkena aksi vandalism. Bangunan yang terkena aksi vandalism tidak memiliki penerangan yang cukup dari prasarana lampu jalan. Penerangan lampu jalan yang tidak memadai memberikan dampak dari kegiatan vandalism tersebut.

\section{Kesimpulan}

Berdasarkan analisa data di atas dapat disimpulkan bahwa kriteria bangunan pada koridor Jalan AM Sangaji yang cenderung menjadi objek dari aksi grafiti tagging adalah: memiliki fungsi bangunan komersial, massa bangunan kecil, tinggi bangunan rendah, warna gelap, transparansi rendah, setback sempit, tidak memiliki ruang terbuka hijau, berada dekat dengan pinggir jalan, dan penerangan gelap.
Faktor setting fisik yang paling berpengaruh terhadap aksi grafiti tagging adalah tidak adanya Ruang Terbuka Hijau (RTH) (85\%), massa bangunan yang kecil (82\%), kurangnya transparansi pada bangunan (80\%), dan setback yang sempit $(80 \%)$.

Hasil verifikasi yang dilakukan dengan cara memberikan kuesioner terhadap pelaku grafiti tagging menunjukkan bahwa motivasi kegiatan mereka tersebut untuk eksistensi diri maupun kelompok. Bangunan yang sering dijadikan aksi grafiti tagging yaitu bangunan yang terletak pada koridor jalan utama dan mempunyai setback yang sempit.

\section{Referensi}

Ardhiansyah, Nino, Dhyah Ayu Retno Widyastuti, and Elisabet Dita Septiari. 2019. 'Perubahan Tata Guna Lahan Kampung Prawirotaman Kota Yogyakarta Sebagai Dampak Keberadaan Kawasan Komersial'. ARTEKS: Jurnal Teknik Arsitektur 3 (2): 149-58. https://doi.org/10.30822/arteks.v3i2.66.

Carollina, Donna. 2017. 'Pemanfaatan Sampah Spraycan Sebagai Katalog Pameran "Voice of Wall 6 Hours Exhibition"'. Jurnal Bahasa Rupa 1 (1): 35-42. https://doi.org/10.31598/bahasarupa.v1i1.145

Dianty, Grace Putri, and Yohanes Basuki Dwisusanto. 2020. 'Aktivitas Di Alun-Alun Sebagai Ruang Terbuka Publik Dengan Konsep Lapangan, Kasus Studi: Alun-Alun Bandung'. ARTEKS : Jurnal Teknik Arsitektur 5 (1): 47-56. https://doi.org/10.30822/arteks.v5i1.116.

Fimela. 2013. 'Graffiti, Seni Jalanan Pewarna Ruang Dan Dinding Hampa Ibukota'. Fimela: News and Entertainment. 2013. https://www.fimela.com/newsentertainment/read/3509094/graffiti-senijalanan-pewarna-ruang-dan-dinding-hampaibukota.

Griffith, Robin, and J. M. Shapland. 1979. The Vandal's Perspective: Meanings and Motives, Designing Against Vandalism. Edited by Jane Sykes. London: The Design Council.

Hantono, Dedi, and Diananta Pramitasari. 2018. 'Aspek Perilaku Manusia Sebagai Makhluk Individu Dan Sosial Pada Ruang Terbuka 
Publik'. Nature: National Academic Journal $\begin{array}{llll}\text { of } \quad \text { Architecture } 5 & \text { (2): } 85 .\end{array}$ https://doi.org/10.24252/nature.v5i2a1.

Jacobs, Allan B. 1995. Great Streets. Illustrate. Cambridge, England: MIT Press.

Krier, Rob. 1991. Urban Space. Hongkong: Rizzoli International Publication Inc.

Kurniasari, Triliana, Taufik Suprihatini, and Triyono Lukmantoro. 2013. 'Eksistensi Graffiti Sebagai Media Ekspresi Subkultur Anak Muda'. Interaksi Online 12 (2). https://ejournal3.undip.ac.id/index.php/intera ksi-online/article/view/2127.

Lexy, J. Moleong. 1994. Metodologi Penelitian Kualitatif. Bandung: PT. Remaja Rosda Karya.

https://doi.org/10.1016/j.carbpol.2013.02.055

Liem, Yoseph, and Reginaldo Chistophori Lake. 2018. 'Pemaknaan Ruang Terbuka Publik Taman Nostalgia Kota Kupang'. ARTEKS: Jurnal Teknik Arsitektur 2 (2): 149-58. https://doi.org/10.30822/arteks.v2i1.48.

Mushtaha, Emad, and Faisal Hamid. 2016. 'The Effect on Vandalism of Perception Factors Related to Housing Design, Case of U.A.E Cities'. Journal of Asian Architecture and Building Engineering 15 (2): 247-54. https://doi.org/10.3130/jaabe.15.247.

Muttaqin, Muhammad Iqbal. 2009. "Kromonisasi Vandalisme", Siasat Seni Komunitas Jogja Street Art Graffiti Dalam Merebut Ruang Publik'. Universitas Islam Negeri Sunan Kalijaga. http://digilib.uinsuka.ac.id/3176/1/BAB I\%2C V.pdf.

Salmah, Sri. 2015. 'Perilaku Vandalisme Remaja Di Yogyakarta Youth Vandalism Attitude in
Yogyakarta'. Media Informasi Penelitian Kesejahteraan Sosial 39 (1): 15-29.

Sirvani, Hamid. 1985. The Urban Design Process. New York: Van Nostrand Reinhold Company.

Subandriyo, Toto. 2002. 'Rubrik Kotaku Kotamu: Tangan-Tangan Setan Di Atas Budaya'. Harian Kompas, Lembar Jateng Dan DIY, March 2002.

Subroto, T. Yoyok Wahyu. 2019. 'Koeksistensi Alam Dan Budaya Dalam Arsitektur'. ARTEKS : Jurnal Teknik Arsitektur 3 (2): vviii. https://doi.org/10.30822/artk.v3i2.244.

Vorobyeva, Irina V., Olga V. Kruzhkova, and Marina S. Krivoshchekova. 2015. 'The Genesis of Vandalism: From Childhood to Adolescence'. Psychology in Russia: State of $\begin{array}{llll}\text { Art } & 8 & \text { (1): } & 139 .\end{array}$ https://doi.org/10.11621/pir.2015.0112.

Wet, Corene De. 2004. 'The Extent and Causes of Learner Vandalism at Schools'. South African Journal of Education 24 (3): 206-11. https://hdl.handle.net/10520/EJC31998.

Wicandra, Obed Bima, and Sophia Novita Angkadjaja. 2005. 'Efek Ekologi Visual Dan Sosio Kultural Melalui Graffiti Art Surabaya'. Jurnal Desain Komunikasi Visual Nirmana 7 (2): 99-108. https://doi.org/https://doi.org/10.9744/nirman a.7.2.

Widodo, Johannes. 2019. 'Human, Nature, And Architecture'. ARTEKS: Jurnal Teknik Arsitektur 3 (2): 145-48. https://doi.org/10.30822/arteks.v3i2.65. 
ARTEKS : Jurnal Teknik Arsitektur, Volume 5 Issue 2 August 2020

pISSN 2541-0598; eISSN 2541-1217 